\section{Nevzat Karabulut}

Received: 19 November 2008

Accepted: 31 December 2008

Published online: 19 February 2009

(C) European Society of Radiology 2009
A reply to this Letter to the Editor is available at doi:10.1007/s00330-008-1315-8

\section{N. Karabulut}

Department of Radiology, Pamukkale University Medical Center,

Denizli, Turkey

N. Karabulut $(\bowtie)$

Şirinköy yolu 2/1 sok. Onelya evleri A-4, 20125 Yenișehir/Denizli, Turkey

e-mail: nkarabulut@yahoo.com

Tel.: +90-258-3733186

\title{
Inferior vena caval blood flow affects the quality of CTPA during pregnancy
}

Sir,

I read with great interest the paper by Drs Schaefer-Prokop and Prokop [1] in the December 2008 issue of European Radiology, highlighting the protocols to optimize the image quality of CT pulmonary angiography (CTPA) in pregnant individuals. I appreciate the authors' editorial work, which comprehensively overviewed the limitations of CTPA related to physiological changes during pregnancy and summarized the options to overcome them.

In an attempt to shed further light on the effect of altered caval blood flow deteriorating the quality of CTPA, I would like to draw attention to a recent paper by Kuzo et al. [2], who quantitatively measured caval blood flow in healthy subjects by velocity-encoded cine MRI. They found that caval blood flow significantly increases during continuous inspiration and decreases during the Valsalva manoeuvre compared with free breathing. When the ratio of inferior vena cava to superior vena cava blood flow was taken into consideration, it increases during continuous inspiration (2.37), and decreases during breath-hold at end inspiration (1.90), breath-hold at end expiration (1.94), and at Valsalva manoeuvre (1.51) compared with free breathing (2.04). They concluded that CTPA should be performed with only a small inspiration or no inspiration before acquiring CT data. It has also been demonstrated by a Doppler study that hepatic venous pulsatility is decreased during pregnancy, being completely flat with increasing gestational age, which is attributed to increased cardiac output and the pressure effects of the enlarged gravid uterus [3]. Similarly, the compliance of the inferior vena cava is likely to be decreased during pregnancy by the same mechanism, leading to continuous forward flow of unopacified blood into the right atrium.

Knowledge of physiological changes taking place during pregnancy will enable us to modify our acquisition protocols accordingly.

\section{References}

1. Schaefer-Prokop C, Prokop M (2008) CTPA for the diagnosis of acute pulmonary embolism during pregnancy. Eur Radiol 18:2705-2708

2. Kuzo RS, Pooley RA, Crook JE, Heckman MG, Gerber TC (2007) Measurement of caval blood flow with MRI during respiratory maneuvers: implications for vascular contrast opacification on pulmonary CT angiographic studies. AJR Am J Roentgenol 188:839-842

3. Pekindil G, Varol FG, Yüce MA, Yardim T (1999) Evaluation of hepatic venous pulsatility and portal venous velocity with Doppler ultrasonography during the puerperium. Eur J Radiol 29:266-269 